\title{
POWER CONTROL IN AN ISLANDED MICROGRID USING VIRTUAL IMPEDANCE
}

\author{
MAJID DASHTDAR, MASOUD DASHTDAR \\ Electrical Engineering Department, Bushehr branch, Islamic Azad University, Bushehr, Iran \\ E-mail: Dashtdar.masoud@gmail.com
}

\begin{abstract}
The common droop method is one of the most effective methods for controlling power-sharing in islanded microgrid. Due to the dependence of the active and reactive power on the voltage and frequency in resistor microgrid, the use of this method in controlling the power-sharing in these types of a microgrid to the undesirable performance of active and reactive power-sharing. In this paper, by applying virtual impedance in the local controller of distributed generation resources, this paper has modified the common droop method and improved power-sharing. The proposed virtual impedance has an adjustable resistor section and a fixed reactance section. Simulation of a typical islanded microgrid in PSCAD /EMTDC software shows that the proposed method is capable of improving the active and reactive power sharing in resistive microgrid controlled by the droop method.
\end{abstract}

Keywords: Resistant islanded microgrid, Power-sharing, Common droop method, Virtual impedance

\section{INTRODUCTION}

Islanded microgrids are very important for providing critical loads without the need for global network accessibility and hence the optimal control and operation of this structure are of great importance [1-2].

One of the issues that have been a major concern for researchers in controlling microgrids is improving the accuracy of power-sharing. Therefore, for the control of power-sharing, a common drop method, which is one of the local control methods, is suggested to be an efficient control method due to the lack of strong communication and control based on local measurements such as voltage and frequency [3-5]. Proper power-sharing means that each of the distributed generation resources contributes to load supply proportional to their power capacity [3]. Since this method can be used to control the reactive power and the active power in voltage and frequency, respectively and since it is valid in resistor microgrids contrary to the above, it is, therefore, necessary to apply this method in controlling the power-sharing. Another complementary method can be used in resistor microgrids. One of the complementary methods is the use of appropriate virtual impedance in controlling distributed generation [6].

The type of impedance must be such that the feed line equivalent impedance including the actual line impedance $\left(Z_{\text {act }}\right)$ and the virtual impedance $\left(Z_{\text {vir }}\right)$ are often inductively independent of each other to control the active and reactive power, as well as to reduce or eliminate power-sharing error, Compensation for physical impedance matching lack of lines [7].
The virtual impedance proposed in this paper is a complex one, in other words, resistance and reactance. Virtual reactance is implemented to validate and increase the accuracy and efficiency of the common droop method, and virtual resistance is implemented to reduce the powersharing error by counteracting the effect of the actual impedance of the feed line. One of the main reasons for using the common droop method is the no need for resistance of the feed line and thus preventing the increase of active power feed line loss [8-9].

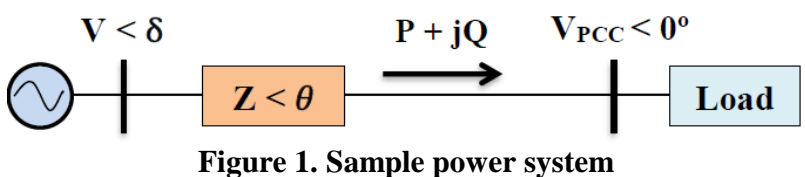

\section{MATHEMATICAL ANALYSIS OF THE POWER-SHARING CHALLENGE}

Generally for a power system such as Figure 1, which have a power source and feeds the load to the PCC through the complex line, the equations for the flow of active power $(\mathrm{P})$ and reactive power $(\mathrm{Q})$ are in Equation (1) and Equation (2) [9]:$$
\mathrm{P}=\frac{\mathrm{V}_{\mathrm{PCC}}}{\mathrm{Z}}\left[\left(\mathrm{V} \cos \delta-\mathrm{V}_{\mathrm{PCC}}\right) \cos \theta+\mathrm{V} \sin \theta \sin \delta\right]
$$

$$
\mathrm{Q}=\frac{\mathrm{V}_{\mathrm{PCC}}}{\mathrm{Z}}\left[\left(\mathrm{E} \cos \delta-\mathrm{V}_{\mathrm{PCC}}\right) \sin \theta+\mathrm{E} \cos \theta \sin \delta\right]
$$

Hence the sharing of reactive power (Q) and active power (P) depends on the impedance of the lines $(\mathrm{X}, \mathrm{R})$ and subsequently, the voltage droop on the lines and the voltage droop $(\Delta \mathrm{V})$ on the line are obtained from the Equation (3):

$$
\Delta \mathrm{V} \approx \frac{\mathrm{XQ}+\mathrm{RP}}{\mathrm{E}_{0}}
$$

In this case, the performance of the common droop method for the proper sharing of both powers is undesirable.

In this paper, using the virtually large virtual reactance, the active power-sharing performance will be improved, in this case, only the reactive power-sharing performance will be dependent on the mismatch of the line voltage droop, which will resolve this problem and compensate for the voltage droop mismatch, Negative virtual resistance is applied. This has several advantages, firstly it reduces the feed line equivalent resistance and also reduces the loss of 
active power, and secondly, by neutralizing the efficiency of the feed line resistance, it improves the performance of the common droop method is often resistant microgrids.

In this assumed scheme, the power capacities of the two distributed generators are identical and their droop characteristic gain is the same and to compensate for the mismatch of the voltage droop to improve the powersharing, the following equations are maintained, that is, the voltage droop on the equivalent impedance of the lines (include sum the actual impedance $\left(\Delta \mathrm{V}_{\mathrm{act}}\right)$ and virtual impedance $\left.\left(\Delta \mathrm{V}_{\text {vir }}\right)\right)$ is the same.

$$
\begin{aligned}
& \mathrm{V}_{1}^{*}=\Delta \mathrm{V}_{\mathrm{act}}^{1}+\Delta \mathrm{V}_{\mathrm{vir}}^{1}+\mathrm{V}_{\mathrm{PCC}} \\
& \mathrm{V}_{2}^{*}=\Delta \mathrm{V}_{\mathrm{act}}^{2}+\Delta \mathrm{V}_{\mathrm{vir}}^{2}+\mathrm{V}_{\mathrm{PCC}}
\end{aligned}
$$

To improve reactive power-sharing you should:

$$
\Delta \mathrm{V}_{\mathrm{act}}^{2}+\Delta \mathrm{V}_{\mathrm{vir}}^{2}=\Delta \mathrm{V}_{\mathrm{act}}^{1}+\Delta \mathrm{V}_{\mathrm{vir}}^{1}
$$

Where $V_{1}^{*}$ and $V_{2}^{*}$ are the voltages generated by the common droop method respectively for each unit and $\mathrm{V}_{\text {PCC }}$ is the voltage measured at the PCC point.

The proposed virtual impedance is used in this paper to generate the virtual voltage droop required to compensate for the mismatch of the line's actual voltage droop. Modeling virtual impedance is provided in the next section.

\section{PROPOSED VIRTUAL IMPEDANCE MODELING}

To compensate for the mismatch of the voltage droop and reduce the power-sharing error, the virtual impedance modeling is performed using the voltage droop generated by it at the stationary reference: [10]

$$
\begin{aligned}
& \quad \Delta \mathrm{V}_{\text {vir }}(\alpha)+\mathrm{j} \Delta \mathrm{V}_{\text {vir }}(\beta)=\left(\mathrm{R}_{\text {vir }}+\mathrm{j} \mathrm{X}_{\text {vir }}\right)\left(\mathrm{i}_{0}(\alpha)+\right. \\
& \left.\mathrm{ji}_{0}(\beta)\right)=\mathrm{j}\left[\mathrm{R}_{\text {vir }} \mathrm{i}_{0}(\beta)+\mathrm{X}_{\text {vir }} \mathrm{i}_{0}(\alpha)\right]+ \\
& {\left[\mathrm{R}_{\text {vir }} \mathrm{i}_{0}(\alpha)-\mathrm{X}_{\text {vir }} \mathrm{i}_{0}(\beta)\right]} \\
& (7)
\end{aligned}
$$

Where $\Delta V_{v i r}(\alpha)$ and $\Delta V_{v i r}(\beta)$ are the voltage droop along the axis $\alpha, \beta$, and $i_{0}$ of the output current of the distributed generator source and $\mathrm{X}_{\mathrm{vir}}$ is the virtual reactance and $\mathrm{R}_{\mathrm{vir}}$ is the virtual resistance. Virtual Reactor $\left(\mathrm{X}_{\mathrm{vir}}=\omega \mathrm{L}_{\mathrm{vir}}\right)$ is applied to validate the common droop method in resistor microgrid and reduce the powersharing sensitivity to the feed line impedance and has a constant and approximately large value and is implemented in the control loop of all distributed generation sources.

Adjustable virtual resistor $\left(\mathrm{R}_{\mathrm{vir}}=-\mathrm{k}_{\mathrm{v}}\right)$ to reduce or eliminate the mismatch of the feed lines impedance and subsequently reducing or eliminating the mismatch of the voltage droop, is implemented in a source control loop with a larger feed line impedance, so variable the virtual resistance $\left(-\mathrm{k}_{\mathrm{v}}\right)$ has a negative coefficient. Determining which sources have larger feed line impedance is done by sampling the voltage and current of each source. As illustrated in Figure 2, how to implement virtual negative resistance.

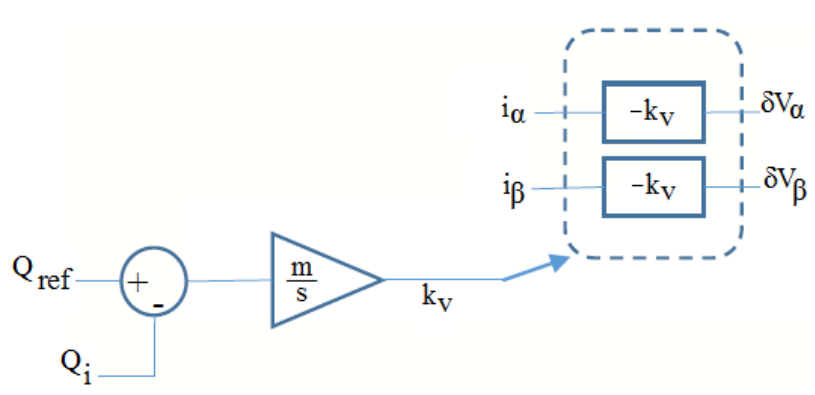

Figure 2. Implementation of adjustable virtual negative resistance.

Due to the purpose of applying the virtual resistor in this paper and the voltage droop generated by it in the following relation, its design is based on the mismatch of the reactive power output $\left(\mathrm{Q}_{\mathrm{i}}\right)$ of the distributed generation sources and hence in obtaining a virtual resistor variable from a simple integrator with $\mathrm{m}$ gain is used to reduce the reactive power-sharing error, resulting in a virtual resistance variable and consequently a virtual voltage droop.

$$
\begin{aligned}
& \delta \mathrm{V}(\alpha)=-\mathrm{k}_{\mathrm{v}} \mathrm{i}_{0}(\alpha) \\
& \delta \mathrm{V}(\beta)=-\mathrm{k}_{\mathrm{v}} \mathrm{i}_{0}(\beta)
\end{aligned}
$$

In Equation 8 and Equation $9, \delta \mathrm{V}(\alpha)$ and $\delta \mathrm{V}(\beta)$ shows the voltage droop due to the difference in impedance of the source feeders on the $\alpha$ and $\beta$ axes. The proposed controller mechanism is that the unit reactive power with the smaller feed line impedance is taken as the reference and the virtual resistance for the other feed source should be adjusted to reduce the reactive power difference of this source to the reactive power of the reference source $\left(\mathrm{Q}_{\text {ref }}\right)$. The result of this variable controller is the virtual resistor which is used for modeling the virtual negative resistor.

Since the virtual resistor is variable, it is possible to follow the changes of the microgrid such as the load change and in these conditions to provide the correct power-sharing.

The implementation steps of the proposed local controller for each of the distributed generation sources, including the common droop controller and the virtual impedance loop, are presented below, which illustrates the structure of this controller in Figure 3.

- Measurement of inverters output voltage and current at three-phase reference; 


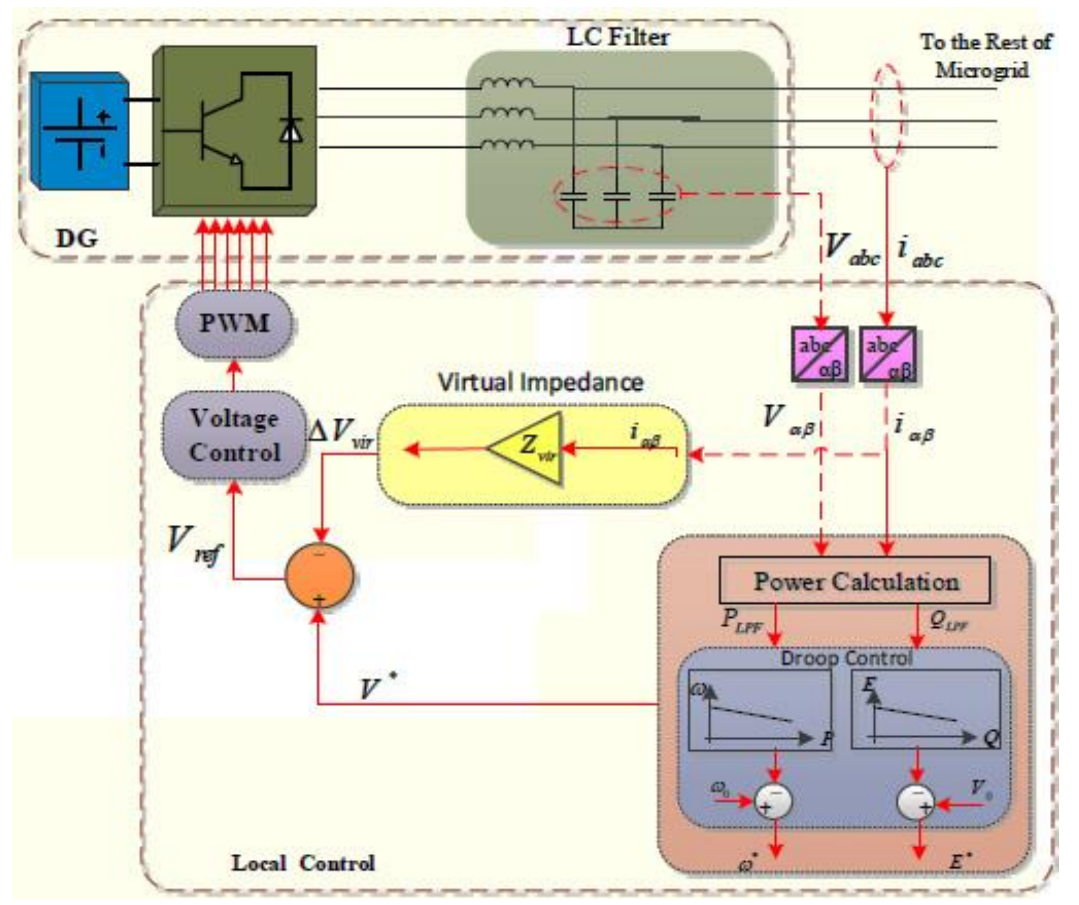

Figure 3. The control structure of each distributed generation source.

- Conversion of three-phase abc current and voltage $\left(\mathrm{V}_{\mathrm{a}, \mathrm{b}, \mathrm{c}}, \mathrm{I}_{\mathrm{a}, \mathrm{b}, \mathrm{c}}\right)$ components to static reference $\alpha-\beta$ components $\left(\mathrm{V}_{\alpha, \beta}, \mathrm{I}_{\alpha, \beta}\right)$;

- Calculate the instantaneous active and reactive power of distributed generation sources;

- Instantaneous power passing through a low-pass filter to calculate average power $\left(\mathrm{P}_{\mathrm{LPF}}, \mathrm{Q}_{\mathrm{LPF}}\right)$;

- Apply a common droop method to calculate frequency $\left(\omega^{*}\right)$ and amplitude $\left(\mathrm{E}^{*}\right)$ of the reference voltage $\left(\mathrm{V}^{*}\right)$. Here $\mathrm{V}_{0}$ and $\omega_{0}$ are the rated voltage and frequency of the network;

- Consider the virtual impedance for the correction of the reference voltage $\left(\mathrm{V}^{*}\right)$ obtained from the common droop method and to generate the final reference voltage $\left(\mathrm{V}_{\text {ref }}\right)$ [11-14].

\section{SIMULATION RESULTS}

A microgrid containing two inverter-based distributed generation sources is simulated in PSCAD/EMTDC software as shown in Figure 4. The system parameters are shown in Table 1.

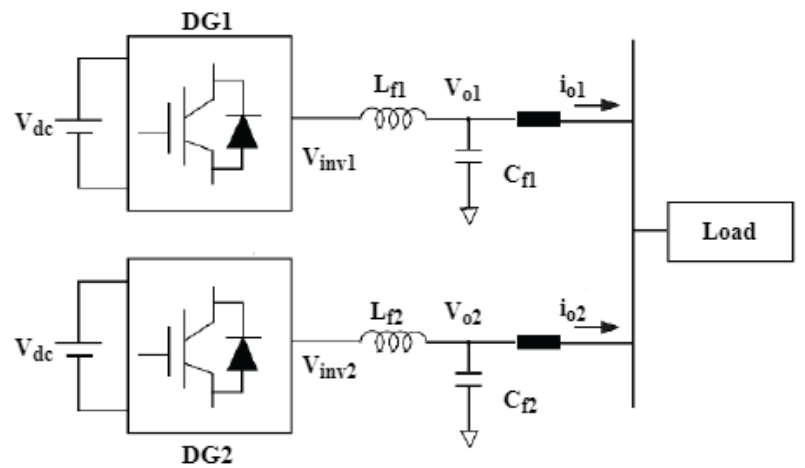

Figure 4. Simulated microgrid.
It is expected that by improving the common droop method using the virtual impedance loop in the local controller, the mismatch of the voltage droop compensating and the reactive power-sharing will be corrected, which results in the simulation showing the good performance of the proposed method.

Table 1. Microgrid parameters with 2 DG units along with their values

\begin{tabular}{|c|c|c|}
\hline \multicolumn{2}{|r|}{ Parameters } & \multirow{2}{*}{ Value } \\
\hline Symbol & Quantity & \\
\hline $\mathrm{V}_{\mathrm{dc}}$ & DC link voltage & 170 \\
\hline $\mathrm{V}_{0}$ & Network line nominal voltage (RMS) & $104 \mathrm{~V}$ \\
\hline Vmin & Minimum microgrid voltage & $98 \mathrm{~V}$ \\
\hline$\omega_{0}$ & Network nominal frequency & $120 \pi \mathrm{rad} / \mathrm{s}$ \\
\hline$\omega_{\min }$ & Minimum microgrid frequency & $119 \pi \mathrm{rad} / \mathrm{s}$ \\
\hline $\begin{array}{l}\mathrm{P}_{\max }, \\
\mathrm{Q}_{\max }\end{array}$ & Maximum DGs power & $\begin{array}{c}500 \mathrm{~W}, 225 \\
\text { Avr }\end{array}$ \\
\hline $\mathrm{C}_{\mathrm{f}}$ & Inverter output filter capacitor & $40 \mu \mathrm{F}$ \\
\hline $\mathrm{L}_{\mathrm{f}}$ & Inverter output filter inductor & $5 \mathrm{mH}$ \\
\hline $\mathrm{R}_{\mathrm{v} 1}$ & Virtual resistance of the first unit & $0.19 \Omega$ \\
\hline $\mathrm{L}_{\mathrm{v} 1}$ & Virtual inductance of the first unit & $2 \mathrm{mH}$ \\
\hline $\mathrm{R}_{\mathrm{v} 2}$ & Virtual resistance of the second unit & $0.665 \Omega$ \\
\hline Lv2 & Virtual inductance of the second unit & $7 \mathrm{mH}$ \\
\hline$Z_{\text {line }}$ & Line impedance & $\begin{array}{c}1 \Omega, 0.25 \\
\mathrm{mH}\end{array}$ \\
\hline $\mathrm{k}_{\mathrm{pv}}$ & $\begin{array}{l}\text { Proportional coefficient of voltage } \\
\text { controller }\end{array}$ & 0.15 \\
\hline $\mathrm{k}_{\mathrm{iv}}$ & Integral coefficient of voltage controller & 9.5 \\
\hline $\mathrm{k}_{\mathrm{pI}}$ & $\begin{array}{l}\text { Proportional coefficient of current } \\
\text { controller }\end{array}$ & 9.5 \\
\hline $\mathrm{k}_{\mathrm{iI}}$ & Integral coefficient of current controller & 200.5 \\
\hline$\omega_{\mathrm{f}}$ & Cut-off frequency to calculate power & 30 \\
\hline$\omega_{\mathrm{c}}$ & $\begin{array}{l}\text { Cut-off frequency to resonant bandwidth } \\
\text { control }\end{array}$ & 10 \\
\hline
\end{tabular}




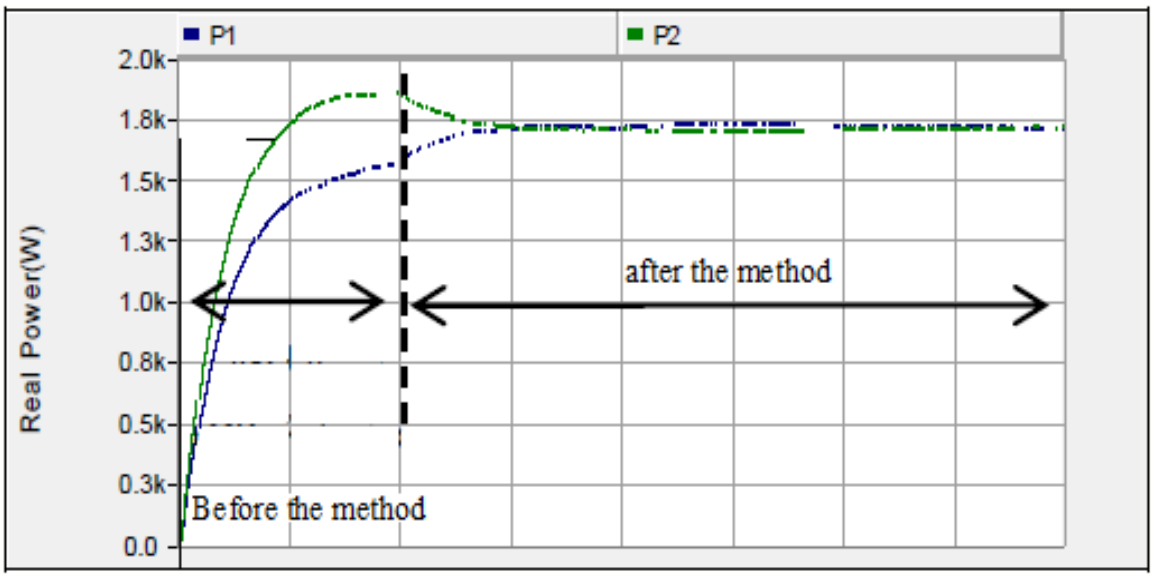

Figure 5a. Active power-sharing function.

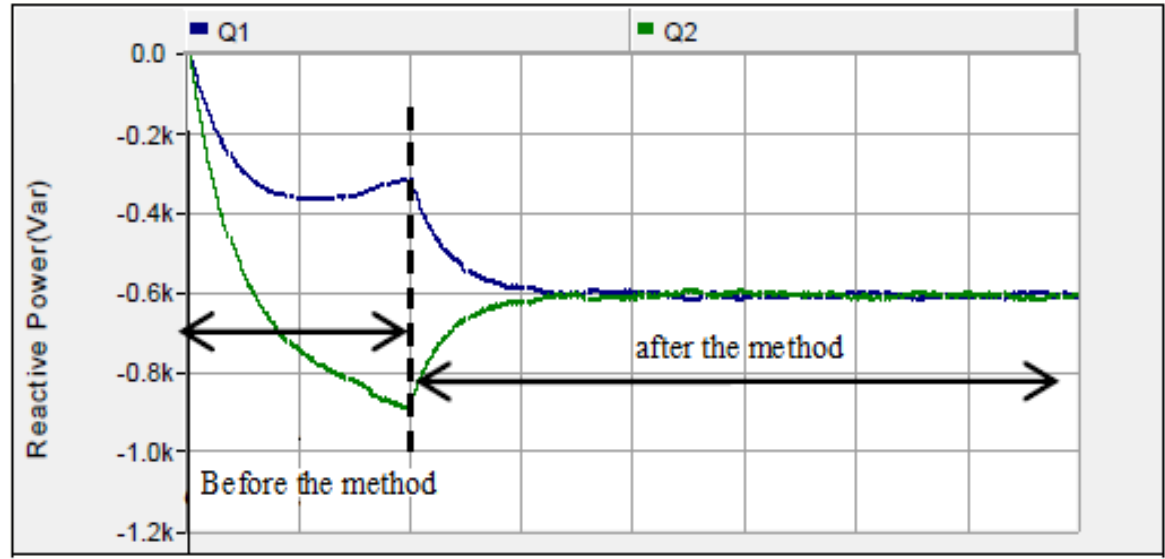

Figure 5b. Reactive power-sharing function.

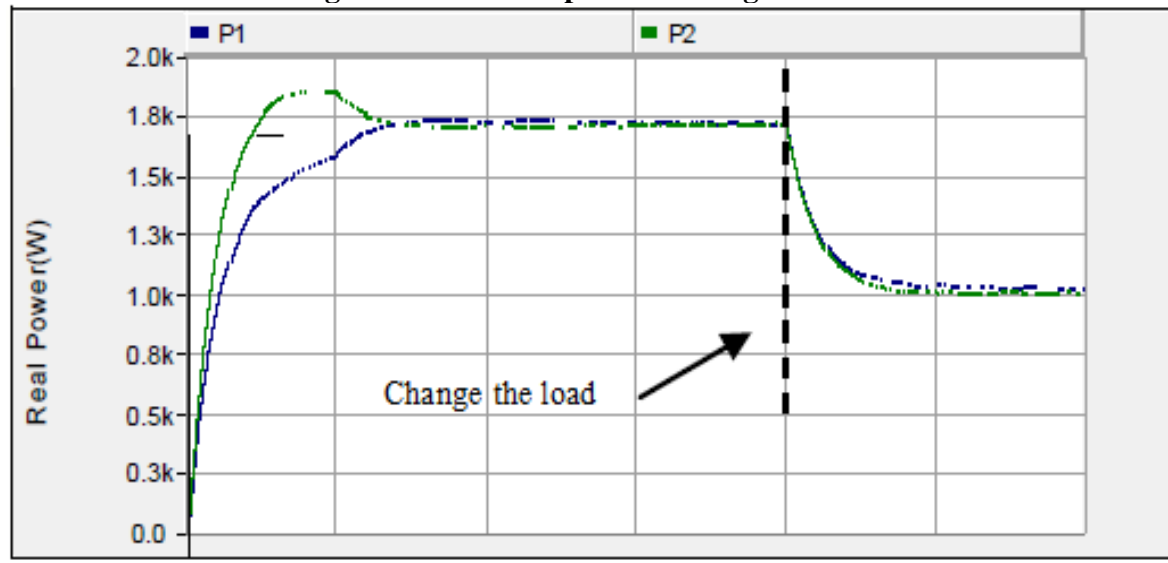

Figure 6a. Active power-sharing function considering load change.

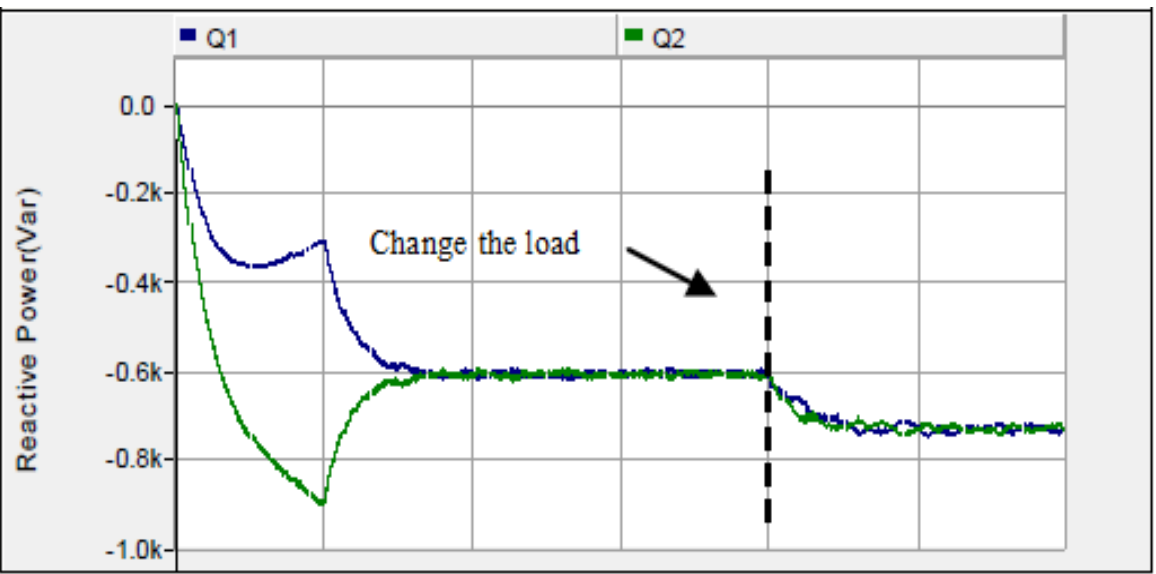

Figure 6b. Reactive power-sharing function considering load change. 
Figure 5a and Figure 5b show the performance of the active and reactive power-sharing, respectively, before and after adding the proposed virtual impedance. As can be seen by applying the proposed virtual impedance method, the common droop method has been improved and the correct power-sharing has been achieved.

To evaluate the performance of the proposed method concerning load change, the constant impedance load of the microgrid has been changed from $8+\mathrm{j} 0.01 * 2 \pi f$ to $10+$ $\mathrm{j} 0.025 * 2 \pi f$.

As shown in Figure 6a and Figure 6b, since the virtual resistor is configurable, the proposed method can track microgrid changes such as load changes, resulting in a proper sharing of the reactive and active power create.

Therefore, it can be concluded that the proposed virtual impedance must necessarily have a variable and adjustable item, not a fixed parameter. Therefore, in this paper, in terms of mismatch of feed lines impedance, the virtual impedance for correct reactive power-sharing is adjusted to compensate for mismatch of feed lines voltage droop under normal microgrid operation conditions or changes in it.

\section{CONCLUSION}

In this paper, to improve the accuracy of the common droop method in an islanded microgrid with high resistivity feed line, a controller with the implementation of a virtual impedance method with constant virtual positive reactance and adjustable virtual negative resistance is proposed. This strategy is presented to accurately adjust the voltage of critical loads and divide the active and reactive loads between the resources based on their capacity, which has three stages. In step 1, the voltage droop across the feeder impedance is estimated and added to the reference voltage. Also, the V-Q droop control coefficient is considered as modified and the voltage droop on the virtual impedance is considered to adjust the critical load voltage in the nominal value. In step 2 , the virtual impedance control loop of the active and reactive is separately controlled and the rotational current between sources is reduced. In step 3, the active and reactive powers are divided between the sources by using voltage and current control loops. The proposed method was evaluated in the presence of microgrid load change and the results of simulation in PSCAD/EMTDC software showed that the proposed method had a good performance and was able to perform the active and reactive powersharing well.

\section{REFERENCES}

[1] Series, I. R. E. "Microgrids and active distribution networks." The institution of Engineering and Technology (2009).

[2] Kim, Jaehong, Josep M. Guerrero, Pedro Rodriguez, Remus Teodorescu, and Kwanghee Nam. "Mode adaptive droop control with virtual output impedances for an inverter-based flexible AC microgrid." IEEE Transactions on power electronics 26, no. 3 (2010): 689-701.

[3] Mahmood, Hisham, Dennis Michaelson, and Jin Jiang. "Accurate reactive power sharing in an islanded microgrid using adaptive virtual impedances." IEEE Transactions on Power Electronics 30, no. 3 (2014): 1605-1617.

[4] Zhu, Yixin, Fang Zhuo, Feng Wang, Baoquan Liu, and Yangjie Zhao. "A wireless load sharing strategy for islanded microgrid based on feeder current sensing." IEEE Transactions on Power Electronics 30, no. 12 (2014): 6706-6719.

[5] Zhang, Huaguang, Sunghyok Kim, Qiuye Sun, and Jianguo Zhou. "Distributed adaptive virtual impedance control for accurate reactive power sharing based on consensus control in microgrids." IEEE Transactions on Smart Grid 8, no. 4 (2016): 1749-1761.

[6] Yao, Wei, Min Chen, José Matas, Josep M. Guerrero, and Zhao-Ming Qian. "Design and analysis of the droop control method for parallel inverters considering the impact of the complex impedance on the power sharing." IEEE Transactions on Industrial Electronics 58, no. 2 (2010): 576-588.

[7] Zhang, Jiyuan, Jie Shu, Jia Ning, Lei Huang, and Hao Wang. "Enhanced proportional power sharing strategy based on adaptive virtual impedance in lowvoltage networked microgrid." IET Generation, Transmission \& Distribution 12, no. 11 (2018): 2566-2576.

[8] Vandoorn, Tine L., Jeroen DM De Kooning, Bart Meersman, Josep M. Guerrero, and Lieven Vandevelde. "Automatic Power-Sharing Modification of \$P \$ \$V Droop Controllers in LowVoltage Resistive Microgrids." IEEE Transactions on Power Delivery 27, no. 4 (2012): 2318-2325.

[9] Yao, Wei, Min Chen, José Matas, Josep M. Guerrero, and Zhao-Ming Qian. "Design and analysis of the droop control method for parallel inverters considering the impact of the complex impedance on the power sharing." IEEE Transactions on Industrial Electronics 58, no. 2 (2010): 576-588.

[10] He, Jinwei, and Yun Wei Li. "Analysis, design, and implementation of virtual impedance for power electronics interfaced distributed generation." IEEE Transactions on Industry Applications 47, no. 6 (2011): 2525-2538.

[11] Hatziargyriou, Nikos, ed. Microgrids: architectures and control. John Wiley \& Sons, 2014.

[12] Dashtdar, Majid, and Masoud Dashtdar. "Voltage Control in Distribution Networks in Presence of Distributed Generators Based on Local and Coordinated Control Structures." The Scientific Bulletin of Electrical Engineering Faculty 19, no. 2 (2019): 21-27.

[13] HOSSEINIMOGHADAM, Seyed Mohammad Sadegh, Masoud DASHTDAR, Majid DASHTDAR, and Hamzeh ROGHANIAN. "SECURITY CONTROL OF ISLANDED MICRO-GRID BASED ON ADAPTIVE NEURO-FUZZY 
INFERENCE SYSTEM." "Scientific Bulletin": Series CElectrical Engineering and Computer Science, no. 1 (2020): 189-204.

[14] Dashtdar, Masoud, and Majid Dashtdar. "Voltage and Frequency Control of Islanded Micro-grid Based on Battery and MPPT Coordinated Control." Mapta Journal of Electrical and Computer Engineering (MJECE) 1, no. 2 (2020): 18-32. 